\title{
STUDYING THE CHEMICAL COMPOSITIONS OF CHICKEN EGGS FOLLOWING INFECTION WITH INFECTIOUS BRONCHITIS VIRUS
}

\author{
BAYOUMIE, HAA. ; EL NILE M.B. ${ }^{* *}$; L.K. ABD EL-SAMIE ${ }^{* * *}$ and MAHA, M. EL DEIB ${ }^{* * * *}$ \\ ${ }^{*}$ Senior Researcher, Animal Health Res. Inst. Zagazig (Poult. Dis. Dept.) \\ ${ }^{* *}$ Researcher, Animal Health Res. Inst. Zagazig (Chemistry. Dept.) \\ ${ }^{* * *}$ Assistant Consultant of Poult. and Rabbit Dis. (Vet. Hospital) Facult. Vet. Med. Zagazig Univ. \\ ${ }^{* * * * *}$ Colleague of Bio Chem. (Central Lab.) Facult. Vet. Med. Zagazig Univ.
}

\section{ABSTRACT}

Received at: 22/9/2015

Accepted: 18/10/2015
IBV detection and isolation trials was done to set its relationship to the inner egg changes. Rapid hemagglutination (HA) activity after neuraminidase enzyme treatment of the concentrated allantoic fluid (AF) of inoculated embryonating chicken eggs (ECE) can give a positive indication for the presence of IBV. The specificity of rapid HA test was examined with a non-hemagglutinating avian viruses such as infectious bursal disease virus (IBDV). The sensitivity of the test was compared with polymerase chain reaction (PCR). The results showed that this test was specific and had a sensitivity of $100 \%$ for IBV detection. The detected IBV strain from Sharkia governorate was examined molecularly using polymerase chain reaction (PCR) and S-1 partial gene sequence. Sequencing showed that this isolate is an IBV variant 2 that resembles the Egyptian IBV strain (Eg/12120 S/2012 and IS/1494/2006) field strains with 99\% identity. The isolated virus designated (IBVEG/ SHARKIA - F-629-2015) had showed (85.6\%) similarity to the 4/91 variant vaccine, and $(82.9 \%)$ similarity to Dutch variants D-274 vaccinal strain, beside $(82.2 \%)$ similarity to the classical vaccinal strains M-41. MA-5, H120. In the present study the following parameters were investigated (Total Lipid, CholesteroL, Triglycerol, Phospholipids, NEFA, MDA, Albumin protein, Yolk protein and Whole protein beside Calcium, Phosphorus, Magnesium, Manganese, Potassium, Chloride and $\mathrm{PH}$ ). Chemical analysis of egg content may explain that deformed eggs had resulted from inappropriate shell deposition on an unstable watery albumen base helped by the contractility of the oviduct due the disturbance in sodium and potassium pump. Watery albumen had resulted from an increase in PH and changes in sodium, potassium and chlorine concentrations, which leads to massive chemical changes in egg white and yolk. As far we know. This is the first attempt to study the impact of Infectious bronchitis virus (IBV) infection on chicken egg biochemical composition.

Key words: IBV, rapid HA, neuraminidase enzyme treatment for IBV, PCR, Sequencing, Egyptian IBV variant 2.

\section{INTRODUCTION}

IBV is a highly contagious acute viral disease of the upper respiratory tract of chickens, it can also replicate in epithelial tissues of kidneys, gonads and oviduct of chickens causing their pathology and affecting the performance Lee et al. (2004).

IBV causes high morbidity in all ages and high mortality in chickens less than 6 weeks old. In addition, poor egg production with poor quality follows the disease (Cavanagh and Naqi 2003).
The main objective behind this study was to set up and optimize a rapid, accurate, sensitive, specific and inexpensive test for detection of IBV based on observation of HA activity induced after neuraminidase enzyme., and to determine the changes in chemical composition of eggs following IBV infection.

\section{MATERIALS}

\section{Deformed egg samples.}

Thirty deformed egg samples showing (thin shelled, cracked, mottled, or with pale coloration) as (fig-1) 
were collected from a breeder flock suffering a $30 \%$ drop in egg production beside egg deformity.

\section{Control eggs.}

Thirty eggs from a healthy sibling of the previous flock that reared elsewhere were collected to serve as control.

Egg samples were submitted for chemical analysis without delay for the following parameters (Total Lipid, CholesteroL, Triglecerol, Phospholipids, NEFA, MDA, Albumin protein, Yolk protein and Whole protein beside Calcium, Phosphorus, Magnesium, Manganese, Potassium, Chloride and PH at $24^{\circ} \mathrm{C}$ ).

Embryonated chicken eggs (ECE).

Ten-day-old ECE were used for virus isolation trials Cavanagh and Naqi (1997).

\section{Membrane filters.}

Syringe membrane filter $450 \mathrm{~nm}$ Thermo scientific Nalgene. Cat. no. 190-2545 (8-0404-40493).

Infectious bursal disease virus (IBDV).

Virulent IBDV field isolate previously isolated and identified Bayoumie and Mohamed (2008) Animal health Res. Inst. zagazig. was used in the present study, its titer was $10^{5.5} \mathrm{EID}_{50} / 0.1 \mathrm{ml}$.

\section{Chicken RBCS.}

Chicken RBCS were obtained from three 28-day-old specific antibody negative chicken (SAN) raised for this purpose.

\section{Saline.}

Sodium chloride $0.9 \%$ (ADWIC) ${ }^{\circledR}$, Sterile Pyrogen free.

\section{Neuraminidase enzyme.}

Neuraminidase enzyme type $\mathrm{V}$ from Clostridium perfringens (Sigma, St. Louis, MO) N 2876 - 10 un., Lot \# SLBD9831 V, P code 1001685488, was used.

\section{Dialysis hollow fiber role.}

Visking dialysisrole. SERVA electrophoresis Gmbh. $21 \mathrm{~mm}$ diameter lot. 120573 with $1 \mathrm{~nm}$ pore size.

Polyethylene glycol.

Polyethylene glycol powder 6000 (Alpha Chemika) Serial. no. (AL 3120) Batch. no. (p 20911) mfg (2/ 2011), exp. (2/2016).

\section{METHODS}

\section{Sample preparation for ECE inoculation.}

Watery egg albumen from the deformed eggs as seen in fig. (1-3) were diluted to make $10 \% \mathrm{w} / \mathrm{v}$ suspension in saline then filtrated through a $450 \mathrm{~nm}$ syringe membrane filter (Thermo scientific Nalgene). $0.2 \mathrm{ml}$ of the filtered material was inoculated into 10 day old ECE via allantoic sac (AS). Inoculated ECE were incubated at $37^{\circ} \mathrm{C}$.Theallantoic fluids (AFs) from the inoculated ECE were harvested $72 \mathrm{~h}$ post inoculation Momayez et al. (2002). In order to be sure that the sample was not contaminated with hemagglutinating viruses. The harvested AFs were tested for the lack of positive HA activity due to any other hemagglutinating virus before neuraminidase treatment.

\section{Dialyses hollow fiber.}

The harvested allantoic fluids (AFs) of the second passage from the inoculated ECE were placed in the dialyses hollow fiber role and legated then covered for overnight with Polyethylene glycol powder at $4{ }^{\circ} \mathrm{C}$ for virus concentration Trudel and Payment (1980).

\section{Neuraminidase enzyme treatment.}

A working solution $1 \mathrm{U} / \mathrm{ml}$ of neuraminidase was prepared from the vial containing $(10 \mathrm{U} / \mathrm{ml})$ using PBS (pH7.2) as diluent. $25 \mu \mathrm{l}$ of the working solution was mixed with $25 \mu \mathrm{l}$ of the dialysed AFs, and held at $37^{\circ} \mathrm{C}$ for $30 \mathrm{~min}$, and then were placed at $4{ }^{\circ} \mathrm{C}$ for 5 min Momayez et al. (2002).

\section{Rapid HA test.}

Twenty five $\mu$ l of dialysed treated AFs were mixed with $25 \mu \mathrm{l}$ of $5 \%$ suspension of chicken red blood cells. HA reaction was read within $1 \mathrm{~min}$. Clear and consistent HA was considered as positive reaction.

\section{Specificity and sensitivity.}

IBVD of Bayoumie and Mohamed (2008) was propagated on 11dayold ECE via chorioallantoic membrane (CAM), the infected CAMs were harvested, homogenized and clarified by centrifuge after three times of freezing and thawing., then it was $450 \mathrm{~nm}$ membrane filterated (Thermo scientific syringe membrane filter). The supernatant fluid was treated with $1 \mathrm{U} / \mathrm{ml}$ of neuraminidase, as mentioned before then HA rapid test was done.

\section{RNA extraction.}

RNA extraction from the AF from ECE was performed using the QIAamp Viral RNA Mini kit (Qiagen, Germany, GmbH) according to their manufacturer's recommendations. Primer of IBV strains is oligo S-15'-(TGA-AAA-CTG-AACAAAAGA-) 3' and reverse Adzhar et al. (1996), Gelb et al. (2005). The reactions were performed in a T3 thermo cycler (Biometra). The amplicons were separated by electrophoresis on $1.8 \%$ agarose gel (Applichem, Germany, GmbH) along with 100- bp DNA Ladder (Qiagen, Germany, GmbH). Reaction products were stained with ethidium bromide, and visualized with ultraviolet trans illumination. The gel was photographed by a gel documentation system 
(Alpha Innotech, Biometra) and the data were analysed by a computer software (Automatic Image Capture Software, Biosciences, and USA (fig-4).

\section{S1 gene sequencing}

Visualized bands in the agarose gel that are of similar in size to the positive control was excised from the gel. The PCR product is isolated from the agarose gel using a commercial gel extraction kit. Purified PCR products are run on a second $1.5 \%$ agarose nucleic acid stain gel to determine the quantity ofproduct present. Approximately $20 \mu \mathrm{l}$ of PCR product is required for sequencing. Sequencing was performed at NLQP sequencing facility. Assembly and analysis of sequence data were conducted using Bio Edit 5.0 package .Nucleotide and amino acid deduced sequences were aligned using Clustal $\mathrm{X}$ software. Phylogenetic analysis was performed by the neighbour-joining method with 1000 bootstrap replicates with the software MEGA version 3.0 as described by Kumar et al. (2004). Sequence chromatograms areedited using suitable analysis software. Edited IBV sequences were characterised using BLASTn for nucleotide or BLASTp for protein analysis.

\section{Biochemical analysis.}

Lipids extraction for determination of total lipids, Cholesterol, triglycerides was determined by using the methods of Hammad et al. (1996).Total lipids, total cholesterol and triglycerides were determined according to the method described by Young (2001).Non esterified fatty acids (NEFA) were determined according to the method described by Schuster (1979). L-Mlondialdhyde (MDA) was estimated according to Esterbauer et al. (1982). Protein concentration in egg albumin, egg yolk and whole egg was done using Lowry method in which samples are digested in acid according to Al-Ghais, (1995). Calcium, Phosphorus, magnesium, Sodium and Potassium were determined according to Tietez (1986) using spectrophotometer Chem 7 geneses. While chloride was estimated, using Electrogeneses model 2000. manganese was estimated by atomic absorption spectrophotometer model 2380 (PERKINELEMER), $\mathrm{pH}$ was estimated using blood gases.

\section{Statistical analysis.}

Data were statistically analyzed as described by Snedecor and Cochran (1967) using SPSS -14 (2006). Values were used to determine significance.

\section{RESULTS}

Results of the present study is illustrated in tables (1-5) and figs. (1-7).

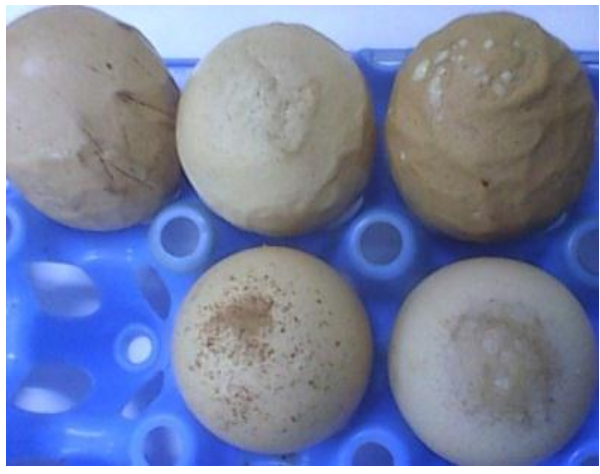

Fig. 1: Shows miss shaped chicken eggs

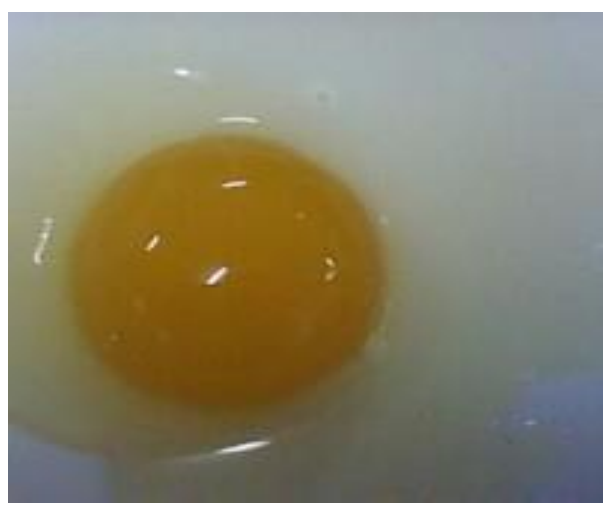

Fig. 3: Shows liquid albumin

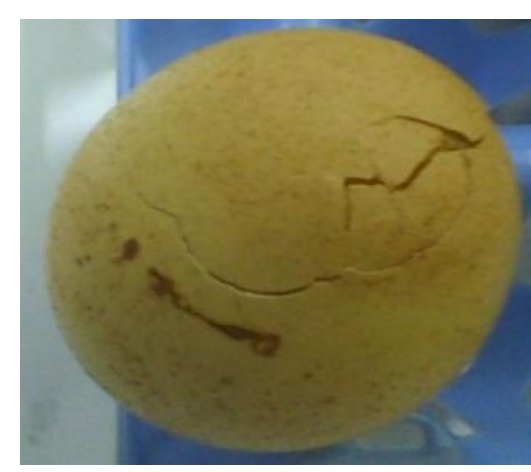

Fig. 2: Shows fragile chicken egg

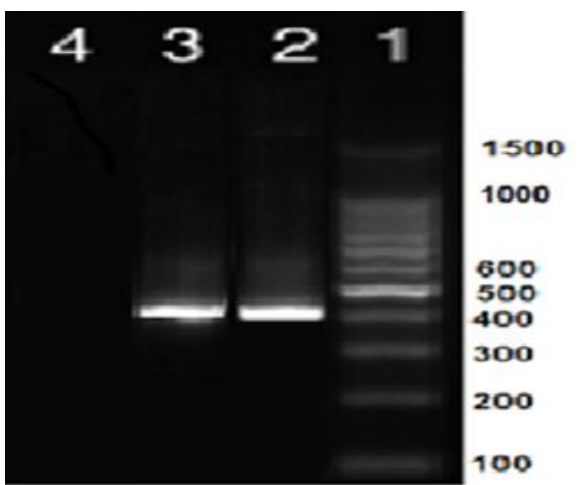

Fig. 4: Shows PCR. Lane 400 bp using a ladder of 100 bp 1- ladder, 2-positive control, 3-sample 
Table 1: Partial nucleotides sequence analysis 400 bp product of S1 gene of (IBV-EG/ SHARKIA -F629-2015).

AACGTATGAGTAGTTTTGTTTATAAACCTTCTGATTTTATGTATGGGTCTTACCACCCGCAGTGTGAT TTTAGACCAGAAACTATTAATAATGGTTTGTGGTTTAATTCTCTATCTGTTTCACTAGCCTATGGGCC TCTACAAGGTGGTTGTAAGCAGTCTGTCTTTAGCAATAGGGCAACGTGTTGTTATGCTTATTCATACA ATGGTCCTCATTTGTGTAAAGGTGTTTATACTGGTGAATTACAACAATATTTTGAATGTGGATTGCTG GTTTATGTAACTAAGAGTGGTGGCTCTCGTATACAAACCAGGAATGAACCACTTGTGTTAACTCATC ACAATTATAATAATATTACTTTGGATAGGTGTGTAGAGCATAATATATATGGCAGGGCCCGGGGGG GGGGGTGGGCCGGGTGAGGAAATTTTTTTTTGAAAAACCCCCCCCCCCCCG

Fig. 5: Nucleotides identities of (IBV-EG/ SHARKIA -F629-2015) with commonly used vaccine strains sequences. Dots indicate residues identical to (IBV-EG/ SHARKIA -F629-2015) Bold letters denotes codon areas. Shaded letters denote sites of differences.

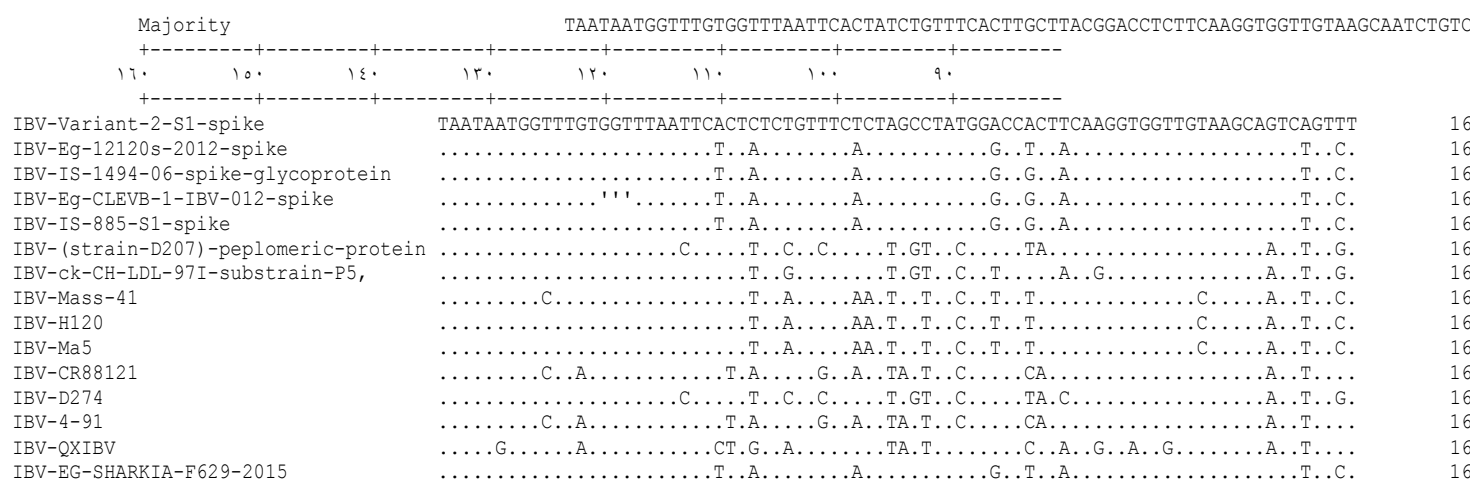

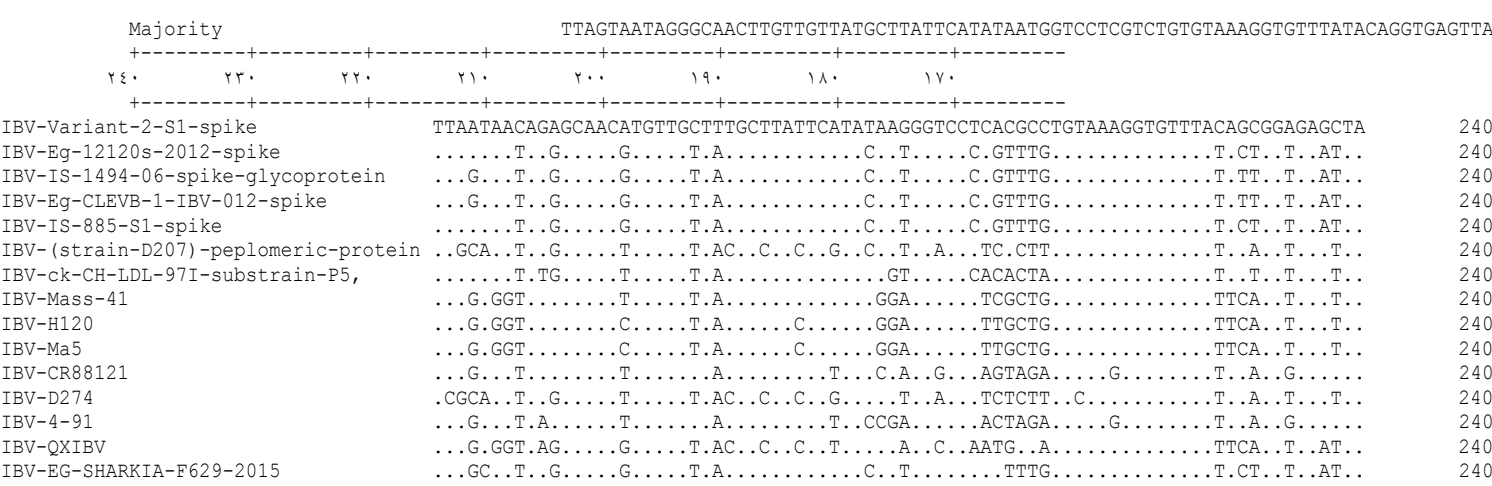

$$
\text { Majority }
$$

CAACAAAATTTTGAATGTGGATTGCTGGTTTATGTAACTAAGAGTGATGGCTCTCGTATACAAACTAGAAATGAACCACT

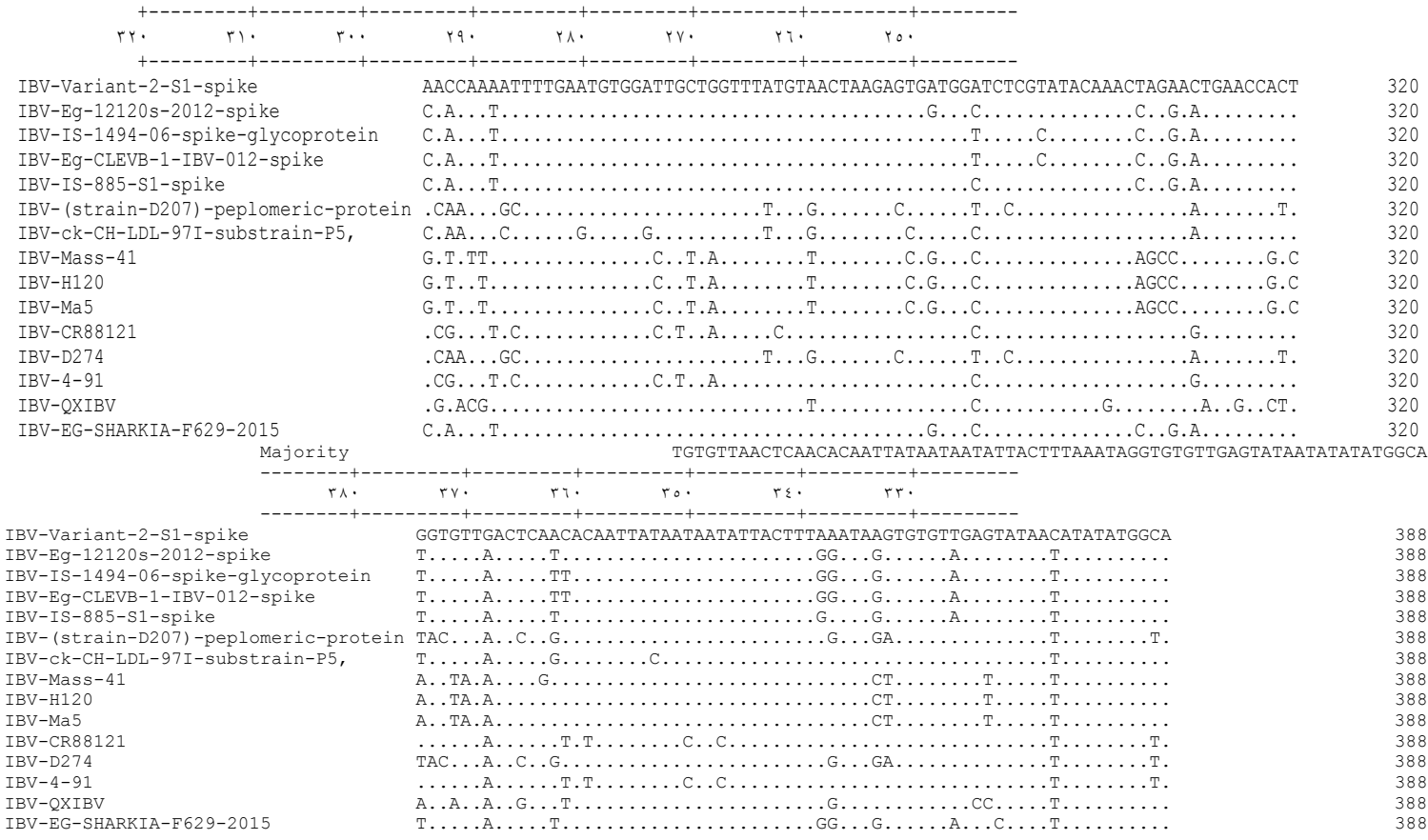


Fig. 6: Amino acid identities of (IBV-EG/ SHARKIA -F629-2015) with commonly used vaccine strains sequences. Dots indicate residues identical to (IBV-EG/ SHARKIA -F629-2015). Potential glycosylation sites (NXS or NXT, except where $\mathrm{X}=\mathrm{P}$ ) are underlined. Shaded letters denote sites of differences. A:Alanine, C:Cysteine, D:Aspartic acid, E:Glutamic acid F:Pheny-lalanine, G:Glycine, H:Histidine, I:Isoleucine, K:Lysine, L:Leucine, M:Methionine, N:Asparagine, P:Proline, Q:Glutamine, R:Arginine, $\mathrm{S}:$ Serine, T:Threonine, V:Valine, W:Tryptophan, Y:tyrosine.

Majority

IBV-Variant-2-S1-spike IBV-Eg-12120s-2012-spike IBV-IS-1494-06-spike-glycoprotein IBV-Eg-CLEVB-1-IBV-012-spike IBV-IS-885-S1-spike

IBV-(strain-D207)-peplomeric-protein IBV-ck-CH-LDL-97I-substrain-P5, IBV-Mass-41

IBV-H120

IBV-Ma5

IBV-CR88121

IBV-D274

IBV-4-91

IBV-OXIBV

IBV-EG-SHARKIA-F629-2015

Majority

IBV-Variant-2-S1-spike IBV-Eg-12120s-2012-spike IBV-IS-1494-06-spike-glycoprotein IBV-Eg-CLEVB-1-IBV-012-spike IBV-IS-885-S1-spike

IBV-(strain-D207)-peplomeric-protein IBV-Ck-CH-LDL-97I-substrain-P5, IBV-Mass-41

IBV-H120

IBV-Ma5

IBV-CR88121

IBV-D274

IBV-4-91

IBV-QXIBV

IBV-EG-SHARKIA-F629-2015
LSSFVYKASDFMYGSYHPSCDFRPETINNGLWFNSLSVSLAYGPLQGGCKQSVFSNRATCCYAYSYNGPSLCKGVYSGEL

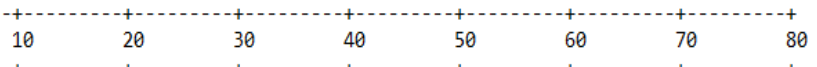

LSSFVYKQSDFMYGSYHPKCNFRPETINNGLWFNSLSVSLAYGPLQGGCKQSVFNNRATCCFAYSYKGPHACKGVYSGEL

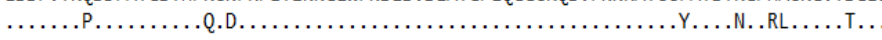

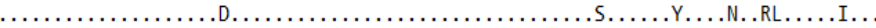
.

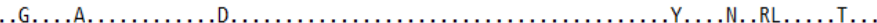

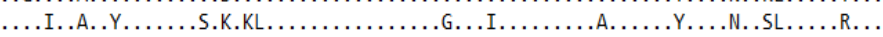

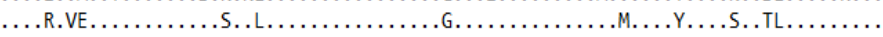

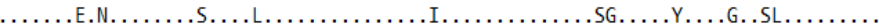

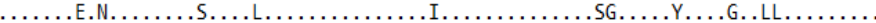

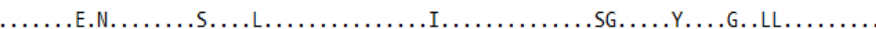

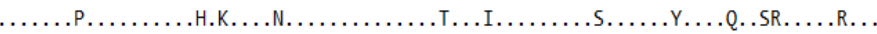

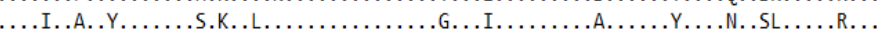

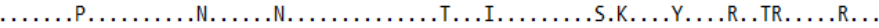

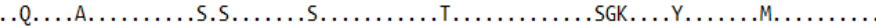

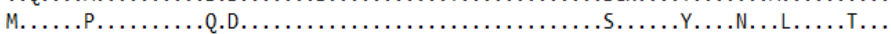

QQYFECGLLVYVTKSDGSRIQTRNEPLVLTQHNYNNITLNRCVEYNIYGT $90 \quad 100 \quad 110 \quad 120 \quad 130$

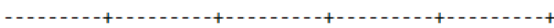
NQNFECGLLVYVTKSDGSRIQTRTEPLVLTQHNYNNITLNKCVEYNIYGT Q.Y...............................DR.......I

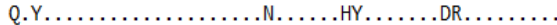

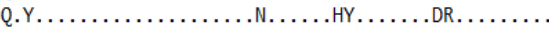

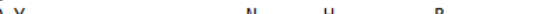

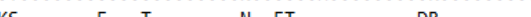

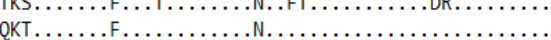
DL................A..P.I.R.........D.....

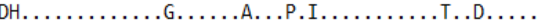

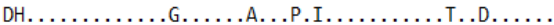

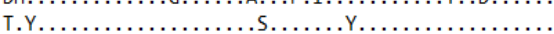

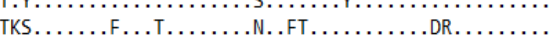

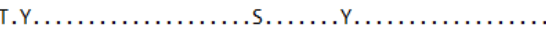

ST....................................

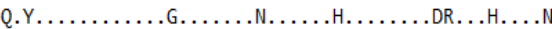

Table 2: Nucleotide (upper right) and amino acid (lower left) of (IBV-EG/ SHARKIA -F629-2015) with selected IBV Vaccines sequences.

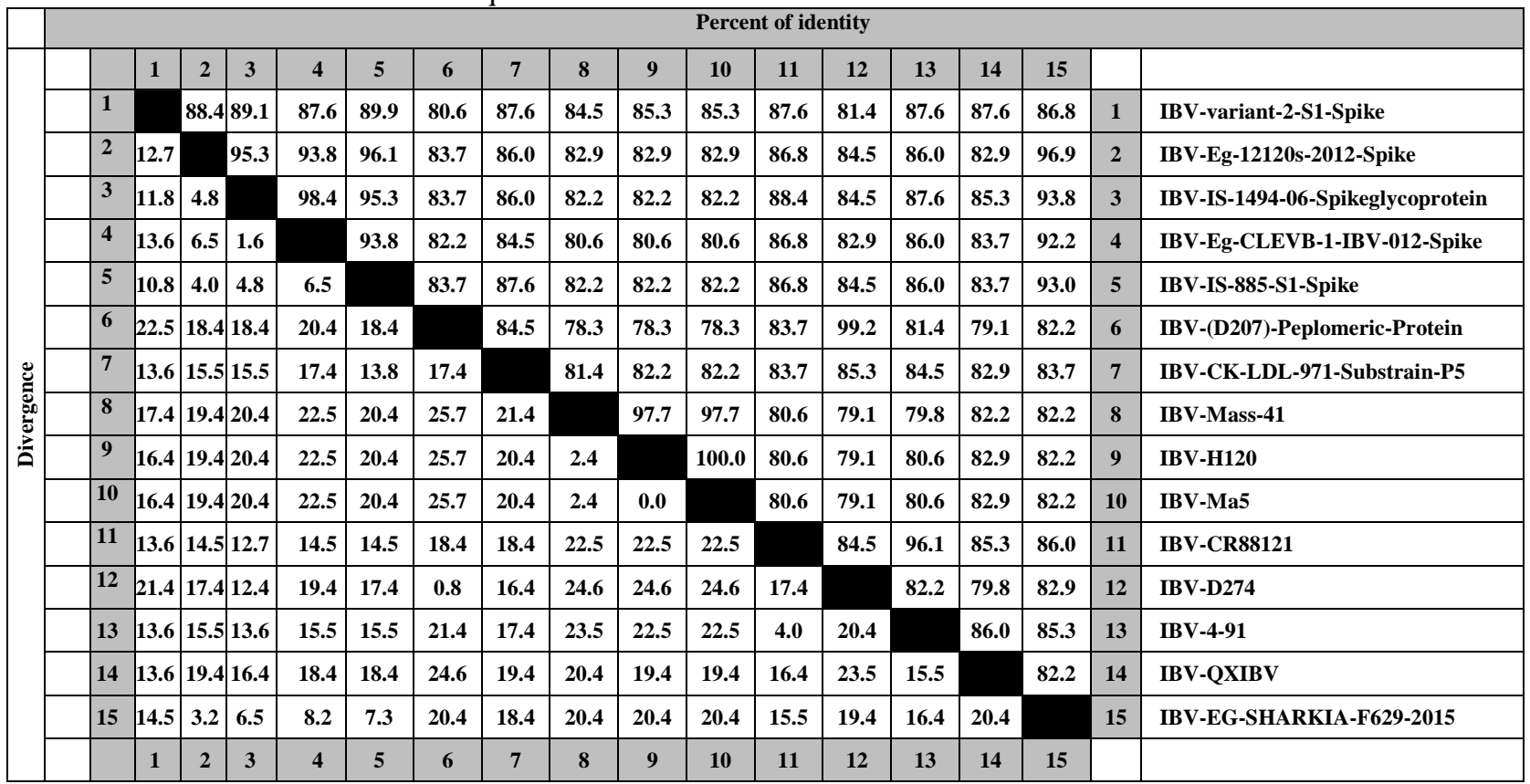




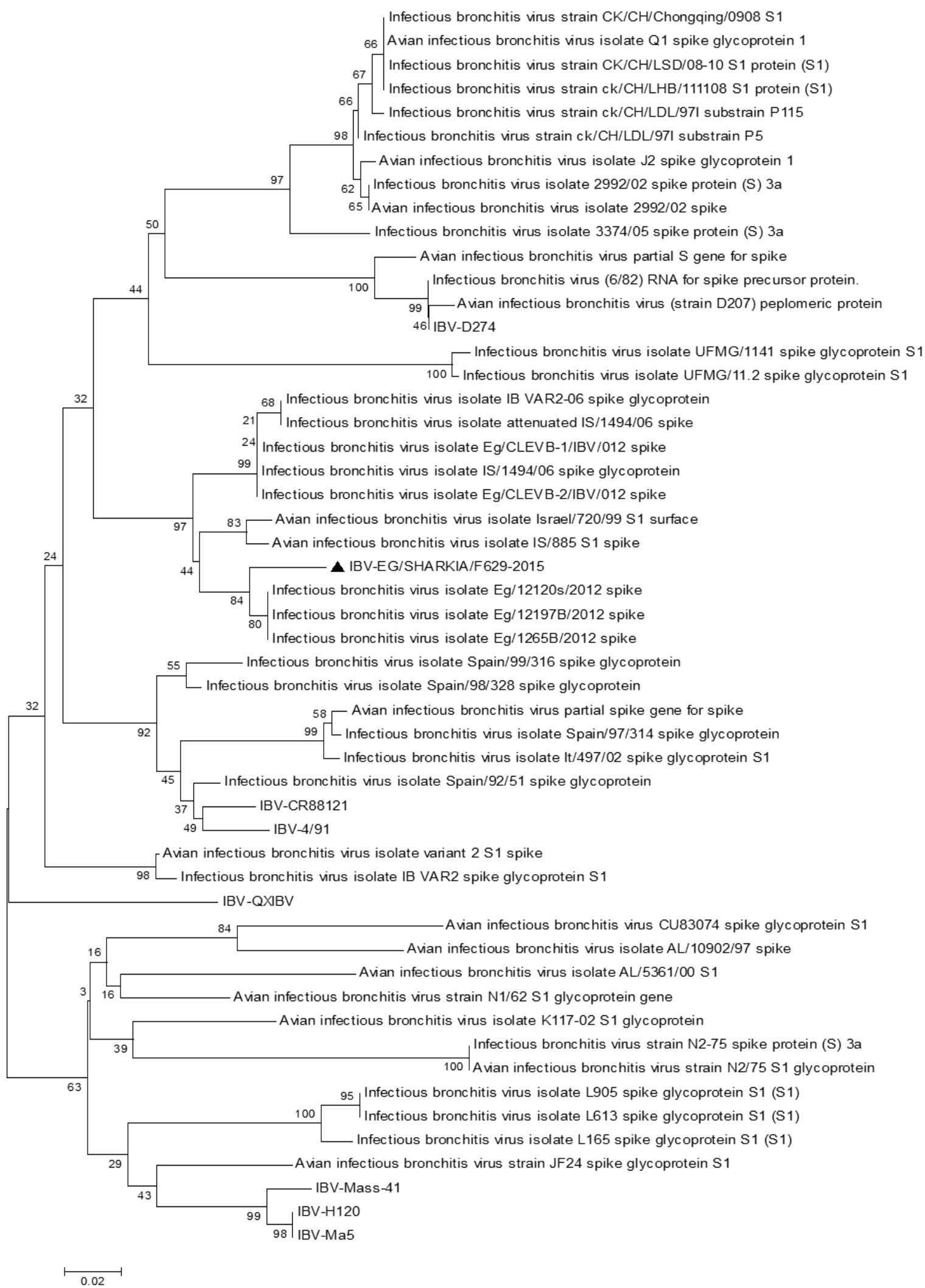

Fig. 7: IBV S1 gene sequence relationships expressed as a phylogenetic tree of (IBV-EG/ SHARKIA -F6292015) isolate and selected IBV reference strains. 
Table 3: Concentrations of Total lipids, total cholesterol, triacylglycerol, Phospholipids and NEFA mg/gm, MDA nmolE/gm in egg yolk in IBV infected birds $(n=5)$.

\begin{tabular}{lll}
\hline Parameters examined & Control & Infected \\
\hline Total Lipid $(\mathrm{mg} / \mathrm{gm}$ yolk) & $\mathbf{6 4 6 . 9 4} * \mathbf{5 0 . 2 2}$ & $\mathbf{5 0 2 . 6 6} \pm \mathbf{2 0 . 2 5}$ \\
\hline CholesteroL $(\mathrm{mg} / \mathrm{gm}$ yolk) & $\mathbf{1 6 1 . 6 2} * * * \pm \mathbf{1 0 . 3 0}$ & $\mathbf{7 9 . 3 1} \pm \mathbf{3 . 0 7}$ \\
\hline Triglecerol $(\mathrm{mg} / \mathrm{gm}$ yolk) & $\mathbf{4 3 8 . 3 0 * * \pm \mathbf { 2 8 . 5 1 }}$ & $\mathbf{2 9 8 . 1 8} \pm \mathbf{2 6 . 0 4}$ \\
\hline Phospholipids $(\mathrm{mg} / \mathrm{gm}$ yolk) & $\mathbf{9 . 2 4} * * \pm \mathbf{0 . 1 8}$ & $\mathbf{8 . 0 3} \pm \mathbf{0 . 2 4}$ \\
\hline NEFA $(\mathrm{mg} / \mathrm{gm}$ yolk) & $\mathbf{0 . 0 9 2} * * \pm \mathbf{0 . 0 0 3}$ & $\mathbf{0 . 0 6 6} \pm \mathbf{0 . 0 0 7}$ \\
\hline MDA (nmolE/gm yolk $)$ & $\mathbf{1 4 . 3 3} * * \pm \mathbf{0 . 6 7}$ & $\mathbf{1 9 . 1 4} \pm \mathbf{0 . 9 8}$ \\
\hline
\end{tabular}

Table 4: Concentrations albumin, yolk and whole egg total protein $\mathrm{mg} / \mathrm{gm}$, beside $\mathrm{PH}$ value at $24{ }^{\circ} \mathrm{C}$ in IBV infected birds $(n=5)$.

\begin{tabular}{lll}
\hline Parameters examined & Control & Infected \\
\hline Albumin protein $(\mathrm{mg} / \mathrm{gm})$ & $\mathbf{1 2 . 2 0} * * \mathbf{0 . 3 3}$ & $\mathbf{9 . 8 2} \pm \mathbf{0 . 4 9}$ \\
\hline Yolk protein $(\mathrm{mg} / \mathrm{gm})$ & $\mathbf{1 4 . 9 8} * * \mathbf{0 . 6 5}$ & $\mathbf{1 1 . 9 6 \pm 0 . 6 2}$ \\
\hline Whole protein $(\mathrm{mg} / \mathrm{gm})$ & $\mathbf{1 3 . 2 4} * \pm \mathbf{0 . 3 1}$ & $\mathbf{1 1 . 9 8} \pm \mathbf{0 . 2 6}$ \\
\hline pH at $24{ }^{\circ} \mathrm{C}$ & $\mathbf{8 . 5 6} \pm \mathbf{0 . 2 4}$ & $\mathbf{9 . 4 8} \pm \mathbf{0 . 1 9}$ \\
\hline
\end{tabular}

Table 5: Concentrations of calcium, phosphorus, magnesium, sodium, potassium and chloride $\mathrm{mg} / \mathrm{gm}$, manganese $\mathrm{ng} / \mathrm{gm}$ yolk in IBV infected birds $(\mathrm{n}=5)$.

\begin{tabular}{lll}
\hline Parameters examined & Control & Infected \\
\hline Calcium (mg/gm yolk) & $1.35 * * \pm 0.054$ & $0.90 \pm 0.047$ \\
\hline Phosphorus (mg/gm yolk) & $5.95 * * * \pm 0.27$ & $4.43 \pm 0.12$ \\
\hline Magnesium (mg/gm yolk) & $0.94 * * \pm 0.17$ & $0.44 \pm 0.21$ \\
\hline Manganese (ng/gm yolk) & $1.60 * * \pm 0.11$ & $1.14 \pm 0.02$ \\
\hline Sodium (mg/gm yolk) & $1.78 * * * \pm 0.017$ & $1.98 \pm 0.026$ \\
\hline Potassium (mg/gm yolk) & $1.25 * * * \pm 0.011$ & $1.17 \pm 0.007$ \\
\hline Chloride (mg/gm yolk) & $1.61 * * \pm 0.064$ & $1.39 \pm 0.016$ \\
\hline
\end{tabular}

* Represents statistical significant at $\mathrm{P}<0.05$ level using T.test.

** Represents statistical significant at $\mathrm{P}<0.01$ level using T.test.

*** Represents statistical significant at $\mathrm{P}<0.001$ level using T.test.

\section{DISSCUSSION}

In the present study detection of (IBV) was intended to insure that IBV had caused the chemical changes found in the examined eggs since different causative agents might be the cause for these changes such as $\mathrm{NDV}, \mathrm{EDS}_{76}$, AIV that might be incriminated with these changes King and Cavanagh (1991), Cavanagh and Naqi (1997). Cavanagh and Naqi (2003).

IBV grows well in the developing ECE compared to chicken organ cultures like chicken kidney and tracheal culture Cook et al. (1976). Upon inoculation by intra allontoic route, no visible changes were observed in first or second passage as previously found by Wang et al. (1996), Arthur Sylvester et al. (2003) and Zanella et al. (2003).

The induction of HA activity for IBV by neuraminidase enzyme is the unique property of Corona viruses Naik et al. (2005). HA activity after treatment with neuraminidase enzyme was used in the present study to detect the presence of IBV in infected allantoic fluid (AF) of ECE after inoculation of IBV suspected materials in ECEvia AS route.
Clear and consistent HA observed after 30min of incubation period with $1 \mathrm{unit} / \mathrm{ml}$ of neuraminidase after the second passage without the need for further passages Momayez et al. (2005). Schultze et al. (1992) mentioned that IBV contains Alpha 2, 3linked $\mathrm{N}$-acetyl neuraminic acid that hinder the viral HA activity. When the virus is treated with crude filtrate of Clostridium perfringens culture, which is believed to contain neuraminidase enzyme, this enzyme, removes the neuraminic acid from the virus surface and induces HA activity. Naik et al. (2005) found that the allontoic fluid collected after 10th passage yielded HA titre of 1:16. This shows the value of virus concentrating of infected AS using the Dialysis hollow fiber role and Polyethylene glycol powder as used by Trudel and payment (1980) and Eweis et al. (2008).

The specificity of rapid HA test was examined with IBDV which revealed non hemagglutinating virus as found also by Momayez et al. (2005).

The sensitivity of the rapid HA test was compared with RT-PCR (fig-2). The results showed that this test was specific and had a sensitivity of $100 \%$ for IBV detection. The results of this study indicate that HA 
test for IBV after neuraminidase treatment is an accurate, sensitive, specific and inexpensive test for rapid detection of IBV these results are comparable to the previous work of Kwon et al.(1993).

In the present study partial PCR for the S 1 gene sequence using universal primers succeeded to amplify the targeted sequence in the tested Sharkia isolates. Sl partial sequence analysis resulted in a PCR product of 400 base pairs (fig-2) thus PCR succeeded to amplify the target sequence in the Sharkia isolates Kingham et al. (2000).

Based on blast analysis and multi sequence alignment of the Sl sequence of the successfully sequenced isolates together with 14 published IBV vaccinal strains, it was demonstrated that isolate is IBV variant 2 resembles the Egyptian IBV strain (Eg /12120 S/2012 and IS/1494/2006) field strains with 99\% identity table (2), (fig5-6). This isolate was designated (IBV-EG/ SHARKIA - F629-2015) had showed $(85.6 \%)$ similarity to the $4 / 91$ variant vaccine, and $(82.9 \%)$ similarity to Dutch variants D274 vaccinal strain, beside $(82.2 \%)$ similarity to the classical vaccinal strains M-41. MA-5, H120 table (2). El-SayedAbdEl Wahab (2015) in a personal communication mentioned that the isolate (IBV-EG/ SHARKIA - F629-2015) formed a similar phylogenetic group with very close similarity to (4/91 and also D-274) IBV.

The S1 sequences of nucleotide sequences of the isolate were aligned with published sequences and the dendrogram was generated to determine the phylogenetic position of these isolates among IBV strains (fig-7).

The obtained results presented in table (3) showed a high significant decrease in concentration of total lipids, triglycerol, Phospholipids and NEFA in IBV affected eggs. This was accompanied by very high significant decrease in yolk total cholesterol concentrations. Meanwhile, a high significant increase in L- malondialdehyde (MDA) concentration was recoded in affected egg group. This increase is a marker of lipid peroxidation and reflects the high production of free radical due to IBV infection. It also reflects the accumulation of free radicals in the blood and tissues of the infected birds Elnile (2008). Further studies are necessary to clarify the effect of IBV in body fluids and tissues after the infection.

In the present study data presented in table (4) showed a high significant decrease in albumin, yolk and whole egg total proteins., while, the $\mathrm{PH}$ value of egg albumin showed a high significant increase at $24 \mathrm{C}^{0}$ compared to the non-infected group. Ivan (2004) recorded that the reduction of albumen proteins changes the structural matrix of the albumen producing watery eggs. Butler et al. (1972) mentioned that microscopic changes such as reduction in the number and height of the epithelial cells., or the complete absence of the cilia, beside glandular hypoplasia caused by IBV maylead to the reduction in the synthesis of albumen proteins especially ovo-mucin, lysozyme and other major proteins which constitute the structural matrix of the thick albumen. Furthermore Muneer et al. (1987) explained that there is a decrease in the proportion of both thick and inner thin albumen, and an increase in the amount of outer thin albumen causing waterywhites and presence of blood or meat spots in the egg albumen.

Obtained data in table (5) in the present study revealed a very high significant decrease in the concentrations of calcium, phosphorus, magnesium and potassium. Moreover, a high significant decrease manganese and chloride concentration was reported. Meanwhile, the concentration of sodium revealed a very high significant increase in egg yolk if compared with the non-infected eggs table (5). The dramatic decrease in the concentrations of calcium, phosphorus, potassium, chloride and manganese concentration, and the very high significant increase in concentration of sodium are probably initiated by a depressed function of the sodium potassium pump and alteration of the activity of sodium potassium AT $\mathrm{P}$ ase. Robinson and Monsey (1972). Solomon (2002) Mentioned that changes observed in the uterine fluid of IBV infected hens could explains the fluidity and thinning of the egg albumin examined from the infected birds. There was deterioration in albumen quality which was reported in the infected hens this finding is attributed to the uterotropism of IBV for the fully functional oviduct Leary (1999). The functional disturbances which followed the virus infection are located in the surface epithelial cells of the uterine mucosa could be explain the depressed function Chousalkar and Roberts (2007). In addition Robinson and Monsey (1972) Reported that the chemical reaction may take place naturally causing liquefaction of thick egg white gel at a relatively high $\mathrm{pH}$ value of 9.2 in egg white. The destruction of the gelatinous nature of thick egg white can occur due to ovomucinlysozyme interaction as the $\mathrm{pH}$ of the albumen changes. It worth to mention that $\mathrm{PH}$ level in the examined infected eggs was $9.48 \pm 0.19$ table (5).

\section{ACKNOWLEDGMENTS}

The authors are grateful to their colleagues at NLQP.

\section{REFRANCES}

Adzhar, A.; Shaw, K.; Britton, P. and Cavanagh, D. (1996): Universal oligonucleotides for the detection of IBVby the polymerase chain reaction. Avian Pathology, 25, 817 -836.

Al-Ghais, S.M. (1995): Heavy metal concentration in the tissues of Sparus Serba (Forkal, 1975) 
from the United Arab Emirates. Bull. Environ. Contam.Toxicol.55: 581.

Arthur Sylvester, A.; Kataria, J.M.; Dhama, K.; Rahul, S.; Bhardwaj, N. and Thomas, S. (2003): Purification of IBV propagated in ECE and its confirmation by RT-PCR. Ind. J. Comp. Microbiol. Immunol. Infect. Dis., 24: 143-147.

Bayoumie, H.A.A. and Mohamed, IAA. (2008): Laboratory evaluation of selected disinfectants on gumboro disease virus. Assuit Vet. Med. J. 55: 231-242.

Butler, E.J.; Curtis, M.J.; Pearson, A.W. and McDougall, J.S. (1972): Journal of the Science of Food and Agriculture 23: 359-369.

Cavanagh, D. and Naqi, S.A. (1997): Infectious bronchitis. In: Diseases of poultry, 10th $\mathrm{cd}$. Calnck B W, H.J. Burncs. C.W. Beard, W.M. Reid, and H.W. Yoder, eds. Iowa State Univ. Press. Ames, IA. Pp.51 1-526. 1997.

Cavanagh, D. and Naqi, S.A. (2003): Infectious bronchitis. In: Y.M. Saif, H.J. Barne, J.R. Glisson, A.M. Fadly, L.R. McDougald and D.E. Swayne, Jr (Eds), Disease of Poultry (11th edn), Pp:101-119. Ames, Iowa State University Press.

Chousalkar, K.K. and Roberts, J.R. (2007): Ultra structural study of infectious bronchitis virus infection in infundibulum and magnum of commercial laying hens. Veterinary Microbiology, 122: 223-236.

Cook, JKA.; Darbyshire, J.H. and Peters, R.W. (1976): The use of chicken tracheal organ culture for the isolation of Avian Infectious Bronchitis virus. Arch. Virol., 50: 109-118.

Elnile M.B. (2008): Biochemical Studies On Lipid Peroxidation And Antioxidant Enzymes In Broiler Chickens Fed On Low Protein Ration. Ph.D Degree of Vet. Med. Sci., (Biochemistry and Clinical Chemistry) Benha University.

El-Sayed M. Abd El-Whab (2015): The Federal Res. Inst. for Animal Health Friedrich-LoefflerInstitut. Inst. of Molecular Virology and Cell Biology AIV Laboratory. Suedufer 10 - Insel Riems. 17493. Germany Greifswald.

Esterbauer, H.; Cheeseman, K.H.; Danzani, M.U.; Poli, G. and Slater, T.F. (1982): Separation and characterization of the aldehyde products of $\mathrm{ADP} / \mathrm{Fe} 2+\mathrm{C}$ stimulated lipid peroxidation in rate liver microsomes. Biochem J., 208: 129-40.

Eweis, M.; Samya, S.; Abdel - Naby and Saber, M.S. (2008): Trials for production of diagnostic kits for RVF virus including highly sensitive and specific antigen for detection of RVF antibodies in domestic animals Egypt. J. Comp. Path. and Clinic. Path. 21; 124-135.

Gelb, J., Jr.; Weisman, Y.; Ladman, B.S. and Meir, R. (2005): S1 gene characteristics and efficacy of vaccination against infectious bronchits virus field isolates from the United states and Israel (1996 to 2000). Avian Pathology, 34: 194-203.

Hammad, S.M.; Siegel, H.S. and Marks, H.L. (1996): Dietary Cholesterol Effects on Plasma and Yolk Cholesterol Fractions in Selected Lines of Japanese Quail. Poultry Sci. 75: 933-942.

Ivan r. Alvarado (2004): IBV. In Vivo and In Vitro Methods of attenuation, And Molecular Characterization Of Field Strains. PHD, Athens, Georgia

King, D.J. and Cavanagh, D. (1991): IBV.In: Diseases of Poultry. $9^{\text {th }}$ ed. B.W. Calnel, H. J. Barnes, C. W. Beard, W.M. Rreid and H. W. Yodler, Jr., eds Iowa state Univ. Press, Ames, Iowa, pp:471-484.

Kingham, B.F., C.L. Keeier. Jr., W.A. Nix, B.S. Ladman. J. Gelb, Jr. (2000): Identification of avian infectious bronchitis virus by direct automated cycle sequencing of the S-1 gene. Avian Dis. 44: 325-335. 2000.

Kumar, S.; Tamura, K. and Nei, M. (2004): Integrated software for Molecular Evolutionary Genetics Analysis and sequence alignment. Briefings in Bioinformatics, 5, 2.

Kwon, H.M.; Jackwood, M.W.; Brown, T.P. and Hilt, D.A. (1993): Polymerase chain reaction and a biotin-labeled DNA probe for detection of infectious bronchitis virus in chickens. Avian Diseases 37: 149-156.

Leary, A. (1999): Factors affecting egg and egg shell quality in several strains of laying hen. $\mathrm{PhD}$ thesis, University of New England.

Lee, CW.; Brown, C.; Hilt, DA. And Jackwood, MW. (2004): Nephro pathogenesis of chickens experimentally infected with various strains of IBV. J. Vet. Med. Sci. 66: 835-840.

Momayez, R.; Gharahkhani, P.; Toroghi, R. and Pourbakhsh, S.A. (2005): Detection of Infectious Bronchitis Virus in Allantioc Fluid by Rapid Hemagglutination Test Arch. Razi Ins. 59 47-54

Momayez, R.; Pourbakhsh, S.A.; Khodashenas, M. and Banani, M. (2002): Isolation and identification of infectious bronchitis virus from commercial chickens. Archives of Razi Institute 53:1-9.

Muneer, M.A.; Newman, J.A.; Halvorson, D.A.; Sivanandan, V. and Coon, C.N. (1987): Effects of infectious bronchitis virus (Arkansas strain) on vaccinated laying chickens. Avian Dis. 31: 820-828.

Naik, B.M.; S.R. Santhosh; B.Y. Sridhar; AshaMayanna, Amitha R. Gomes; B.R. Harish; G.S. Mamatha; S.R. Jayakumar and G. Krishnappa (2005): Isolation of Infectious Bronchitis Virus from an Outbreak in Parent Layer Stock Int. J. of Poult. Sci. 4 (8): 584-585.

Lowry, OH.; Rosebrough, NJ.; Farr, AL. and Randall, RJ. (1951): "Protein measurement 
with the Folin phenol reagent". J. Biol. Chem. 193: 265-275.

Robinson, D.S. and Monsey, J.B. (1972): Changes in the composition of ovomucin during liquefaction of thick white. J. Sci. of Food and Agriculture. 23: 29-38.

Schultze, B.; Cavanagh, D. and Herrler, G. (1992): Neuraminidase treatment of avian IBV Coronavirus reveals a haemagglutinating activity that is dependent on sialic acid containing receptors on erythrocytes. Virology, 189: 792-794.

Schuster (1979): "Estimation of free fatty acids" dim Biochem. S: 24

Snedecor, GW. and Cochran, WG. (1967): Statistical methods, 6TH ed., Univ press, Ames., Iowa. USA.

Solomon, S.E. (2002): The oviduct in chaos. Sci. J., 58: $41-48$.
Tietez, NW. (1986): Clinical guide to Lab. Tests, p.384, W.B. Saunders Co., Philadelphia

Trudle, M. and Payment, p. (1980): Concentration and purification of rubella virus haemagglutinin by hollow fiber ultra-filtration and sucrose density centrifugation. Can. J. Microbiol.26: 1334- 1339.

Wang, C.H.; Hsieh, M.C. and Chang, P.C. (1996): Isolation, Pathogenecity and Protection Efficacy of 120 Infectious Bronchitis Viruses Isolated in Taiwan. Avian Dis., 40: 620-625.

Young, DS. (2001): Effects of disease on Clinical Lab. Tests, 4th ed. vol 1,2edited Washington, DC, AACC Press.

Zanella, A.A. Lavazza; R. Marchi; A. Moreno Martin and F. Pagnelli (2003): Avian Infectious Bronchitis: Charecterization of new isolates from Italy. AvianDis., 47: 180-185.

\section{دراسة التركيب الكيميائي لبيض الاجاج بعد الاصابة بفيروس الالتهاب الثعبي المعدي هام احمد عبد البليع ، محدد بلر عبد العظيم ، لماح كامل عبل السميع ، مها الليب}

Email: heshambayoumie@ yahoo.com_Assiut University web-site: $\underline{\text { www.aun.edu.eg }}$

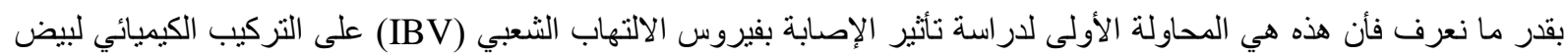

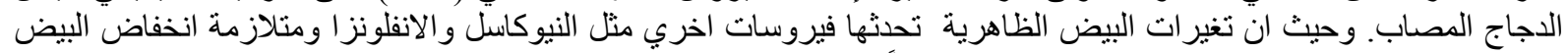

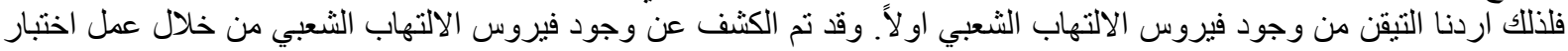

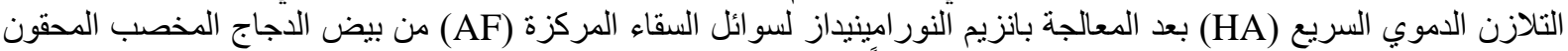

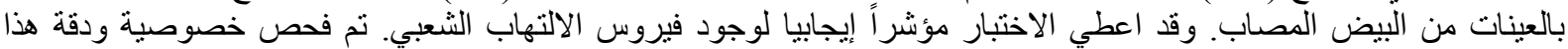

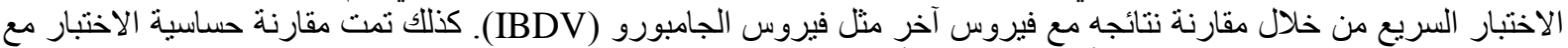

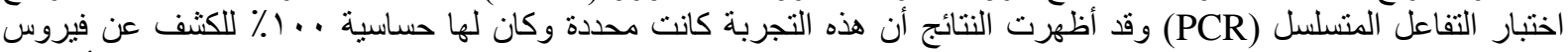

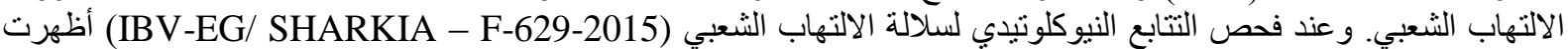
النتائج أن هذا التنسلسل يخص العترة الهصرية المغايرة IBV 2 التي تثبه (Eg /12120 S/2012 and IS/1494/2006) بنسبة

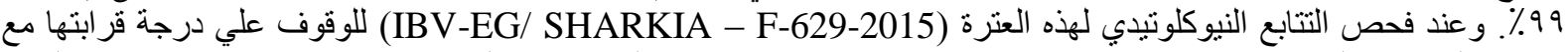

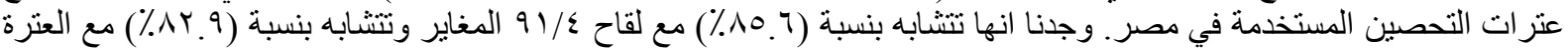

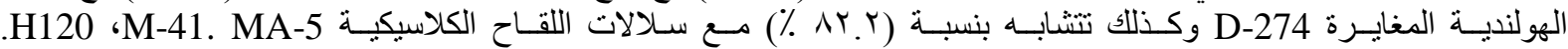

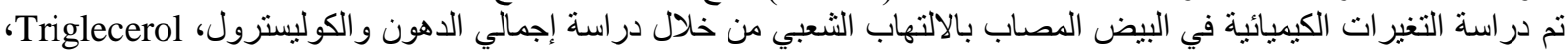

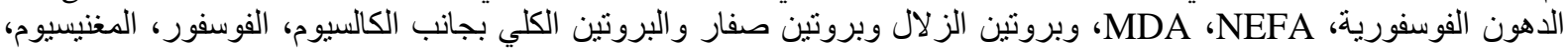

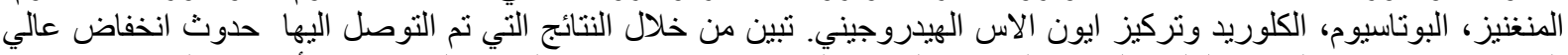

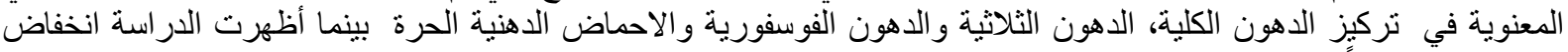

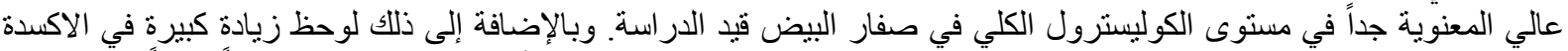

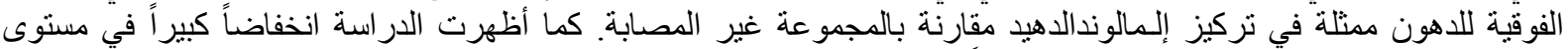

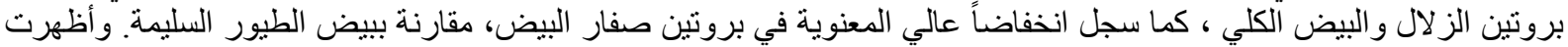

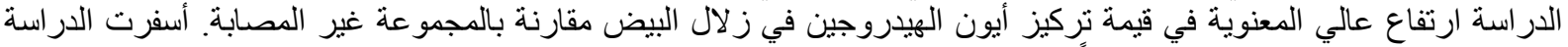

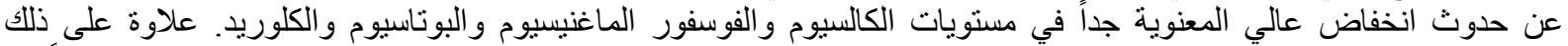

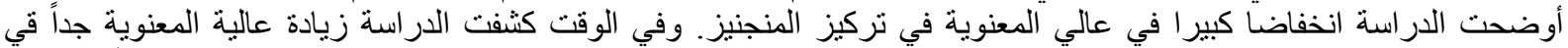

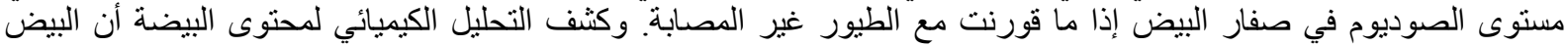

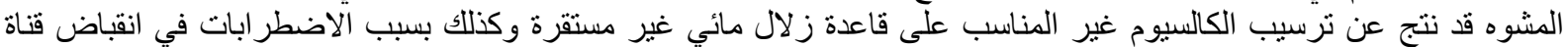

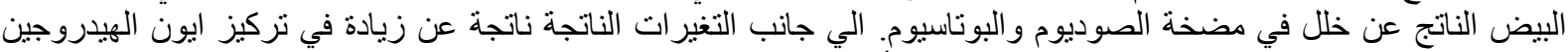

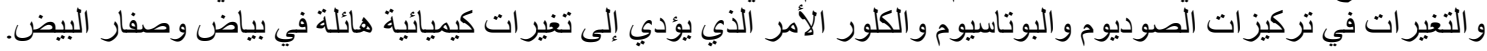

